\title{
Determining the MOV Element Number of Surge Protective Device, Manufactured by Multi-Block MOV Technology
}

\author{
Quyen Huy Anh ${ }^{1}$, Hoang Thi Trang ${ }^{2}$, Le Trong Nghia ${ }^{1}$
}

${ }^{1} \mathrm{HCMC}$ University of Technology and Education

Email: anhqh@hcmute.edu.vn; trongnghia@hcmute.edu.vn

${ }^{2}$ Dong Nai Technology University

Email: hoangthitrang@dntu.edu.vn

\begin{abstract}
SPDs manufactured using multi-block MOV technology can indicate the remaining life (in \%) of the $S P D$, thus helping users to plan appropriate replacement and maintenance. However, because the threshold voltage error of parallel-coupled MOV elements is not the same, the rated impulse current of the SPD manufactured by multi-block MOV technology is not equal to the total of the rated impulse current of parallelcoupled MOV elements. The paper presents the method of determining the number of parallel MOV elements of multi-block MOV according to the allowed dissipation energy method with the help of Matlab software and modelling and simulation technique.
\end{abstract}

Keywords - Surge Protective Device (SPD), Multi-block MOV, Dissipation energy.

\section{INTRODUCTION}

In order to prevent the spread of lightning on low-voltage distribution networks, Surge Protection Device (SPD) are currently popular used, manufactured according to MOV technology, with two types of MOV Single-block and MOV Multi-block [1, 2]. SPDs manufactured with Singleblock MOV technology have large rated impulse current (SPD grade 2, from $40 \mathrm{kA}$ to $100 \mathrm{kA} 8 / 20 \mu \mathrm{s}$ ), but these SPDs are not able to display the remaining life of SPD. This makes it difficult for users to maintain and replace the SPD to ensure the protection level according to the original design.

SPDs are manufactured using multi-block MOV technology, including low lightning dissipation MOV components (8kA $8 / 20 \mu \mathrm{s}$ and $25 \mathrm{kA} 8 / 20 \mu \mathrm{s}$ ) in parallelcoupled to form SPDs with high lightning current dissipation capability like SPD manufactured by Singleblock MOV technology. SPDs manufactured using multiblock MOV technology can indicate the remaining life (in\%) of SPDs, thus helping users to plan appropriate replacement and maintenance. However, because the threshold voltage error of parallel-coupled MOV elements is not the same, the rated impulse current of the SPD manufactured by multi-block MOV technology is not equal to the total of the rated impulse current of parallelcoupled MOV elements [3]. This paper delves into the study and proposes a method for determining the number of MOV elements in parallel-coupled, in order to achieve high amplitude lightning impulse dissipation capability (type I - SPDs I) on the basis of allowed dissipation energy.

\section{MOV MODEL}

The V-I characteristic of MOV in Fig. 1 is represented by the exponential equation [6]:

$$
\mathrm{I}=\mathrm{KV}^{\alpha} \alpha>1
$$

Where: I is the current through MOV, V terminal voltage at MOV, $\mathrm{K}$ is a factor dependent on MOV type, $\alpha$ is the nonlinear factor.

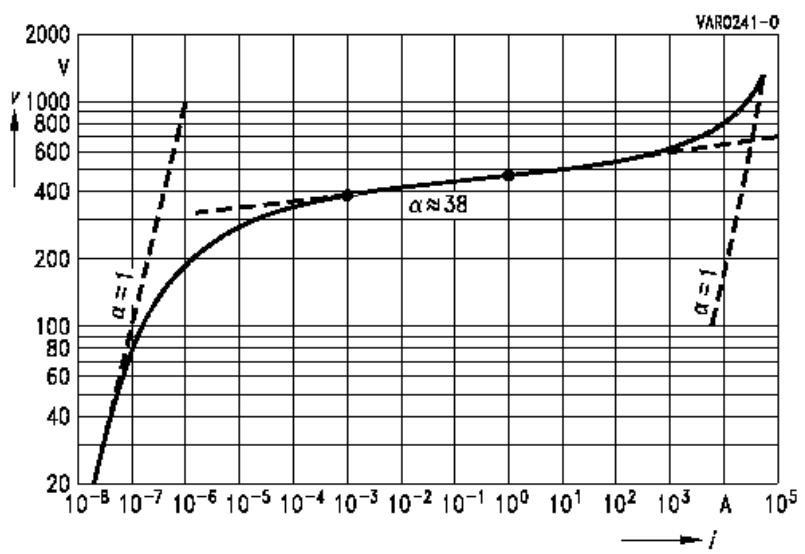

Fig.1 The V-I characteristic of MOV

Manfred Holzer and Willi Zapsky approximate MOV's V-I characteristic by the equation:

$\log \mathrm{V}=\mathrm{B} 1+\mathrm{B} 2 \log (\mathrm{I})+\mathrm{B} 3 \cdot \mathrm{e}-\log (\mathrm{I})+\mathrm{B} 4 \mathrm{e} \log (\mathrm{I})$ with I $>0$ 
Or:

$V=1 \mathrm{O}^{B_{1}+B_{2} \log (I)+B_{3} e^{-\log (I)}+B_{4} e^{\log (I)}}$

Where: The values for B1, B2, B3 and B4 depend on each MOV type.

MOV model can be replaced by equivalent circuit diagram as Fig. 2 [4].

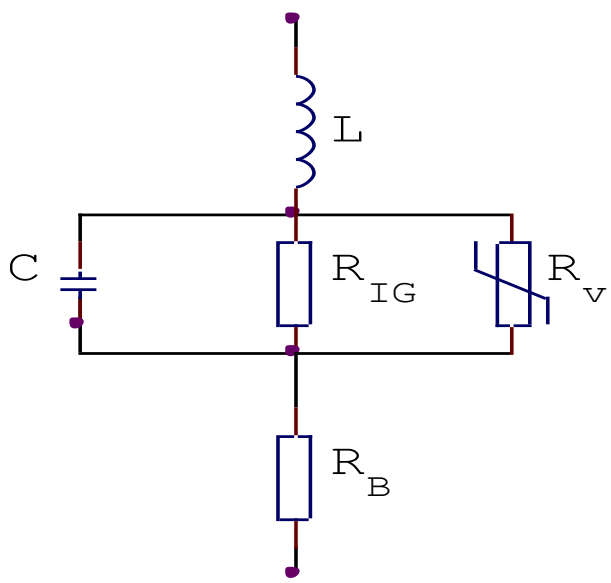

Fig. 2 The equivalent circuit model of $M O V$

Where: $\mathrm{L}$ is the wire inductance ( $\cong 1 \mathrm{nH} / \mathrm{mm}), \mathrm{C}$ is the capacitance of the metal oxide rheostat, $\mathrm{R}_{\mathrm{IG}}$ is the junction resistance between zinc oxide particles $\left(\rho=10^{12} \rightarrow\right.$ $\left.10^{13} \Omega \mathrm{cm}\right), \mathrm{R}_{\mathrm{V}}$ is the ideal rheostat, the nonlinear resistor $(0$ $\rightarrow \infty \Omega), R_{B}$ is the resistor of zinc oxide $(\rho=1 \div 10 \Omega \mathrm{cm})$.

The absorbed energy of MOV is determined by the equation (4):

$$
W=\int_{t 0}^{t 1} v(t) i(t) d t
$$

Where: $v(t)$ is the voltage across MOV during the time that current $\mathrm{i}(\mathrm{t})$ passes.

In order to MOV not to be damaged, the absorbed energy of MOV must not exceed the allowed energy specified by the manufacturer.

\section{DISTRIBUTE CURRENT IN MOVS PARALLEL- COUPLED}

When analysing the heterogeneity of the threshold voltage parameters to the current through the MOV in parallelcoupled of the SPD device consists of $\mathrm{n}$ low voltage MOVs: M1, M2, ...Mi, ...Mn in parallel-coupled (Fig.3). Assume that MOV V1 has a threshold voltage error of $10 \%$, and (n-1) the MOV has the same threshold voltage error of $+10 \%$. When an impulse current $\mathrm{i}$ with a waveform of $8 / 20 \mu$ s passes through them then:

$$
\begin{aligned}
& \mathrm{i}=\mathrm{i}_{1}+\mathrm{i}_{2}+\ldots+\mathrm{i}_{\mathrm{i}}+\ldots+\mathrm{i}_{\mathrm{n}} \\
& \mathrm{v}_{1}=\mathrm{v}_{2}=\ldots=\mathrm{v}_{\mathrm{i}}=\ldots=\mathrm{v}_{\mathrm{n}} \\
& \mathrm{v}_{1}=\mathrm{f}\left(\mathrm{i}_{1}\right) \\
& \mathrm{v}_{\mathrm{i}}=\mathrm{f}\left(\mathrm{i}_{\mathrm{i}}\right) \\
& \mathrm{v}_{\mathrm{n}}=\mathrm{f}\left(\mathrm{i}_{\mathrm{n}}\right)
\end{aligned}
$$

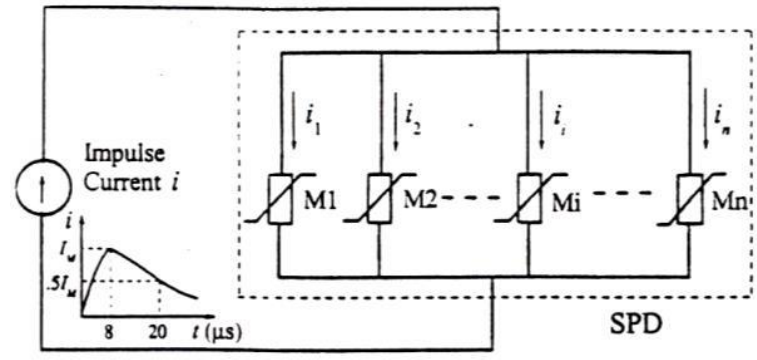

Fig.3 Current distribution of elements in parallel-coupled $M O V$

Where: $i_{1}, i_{2}, i_{i}$ and in are current flowing through MOV $\left(\mathrm{M}_{1}, \mathrm{M}_{2}, \mathrm{M}_{\mathrm{i}}\right.$ and $\left.\mathrm{M}_{\mathrm{n}}\right)$ and $\mathrm{V}_{1}, \mathrm{~V}_{2}, \mathrm{~V}_{\mathrm{i}}$ and $\mathrm{V}_{\mathrm{n}}$ are voltage of $\operatorname{MOV}\left(M_{1}, M_{2}, M_{i}\right.$ and $\left.M_{n}\right)$, corresponding $V_{i}=f\left(i_{i}\right)$ is the current- voltage characteristic MOV $\mathrm{M}_{\mathrm{i}}$, with the currentvoltage relation formula: $i_{i}=C V_{i}^{\alpha}$ with $\mathrm{C}$ is a constant and $\alpha$ is a nonlinear factor.

Found that: when MOV elements are in parallel-coupled, the rated impulse current of the SPD will not be equal to the sum of the rated impulse current of the MOV elements:

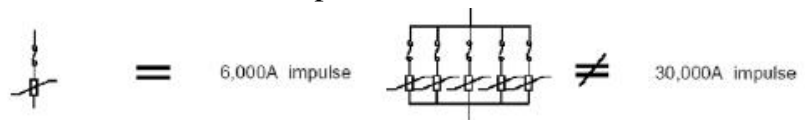

Fig.4 The rated impulse current of the SPD in the case of MOV elements is not homogeneous.

In this case, the ISPD rated impulse current of the surge protective device is not equal to the total impulse current of MOV elements in parallel-coupled:

$$
\mathrm{I}_{\mathrm{SPD}} \neq \mathrm{n} \mathrm{I}_{\mathrm{MOV}}
$$

To keep the parallel MOVs operate safety, the safe reserve of the rated impulse current of the SPD should be considered in the SPD design.

$$
\mathrm{I}_{\mathrm{SPD}}=\mathrm{nk}_{\mathrm{r}} \mathrm{I}_{\mathrm{MOV}}
$$

Where: $k_{r} \geq 1$ is the safety reserve factor of the rated impulse current of the SPD.

\section{DETERMINING THE NUMBER OF N MOVS IN MULTI-BLOCK MOVS ACCORDING TO DISSIPATION ENERGY METHOD}

For multi-block MOV, there are n MOV elements with the following parameters [5]:

- $\quad$ Rated impulse current $I_{1}(\mathrm{kA})$, waveform $8 / 20 \mu \mathrm{s}$.

- The allowed dissipation energy $\mathrm{W}(\mathrm{J})$.

The number of MOV elements of a multi-block MOV with a rated impulse current $\mathrm{I}_{\mathrm{t}}(\mathrm{kA})$ of $8 / 20 \mu$ s waveform can be determined by the following steps:

Building simulation circuit includes:

- $\quad$ Pulse generator $\mathrm{I}_{\mathrm{t}}(\mathrm{kA}) 8 / 20 \mu \mathrm{s}$ waveform.

- Building multi-block MOV model including $n$ MOV elements with rated pulse current $\mathrm{I}_{1}(\mathrm{kA})$, $8 / 20 \mu$ s waveform. In particular, $\mathrm{MOV}_{1}$ has a threshold voltage error of $-10 \%$ and parallel- 
coupled with (n-1) MOV has a threshold voltage error of $+10 \%$.

- Perform the energy dissipation simulation through $\mathrm{MOV}_{1}$ and observe this energy value according to the number of $\mathrm{n}$ changes.

- The simulation process stops when the energy dissipated through $\mathrm{MOV}_{1}$ reaches the permitted value. Then, identify n MOV elements need to be parallel-coupled.

\section{DETERMINE THE ELEMENTS NUMBER OF THE COMMON MULTI-BLOCK MOV}

Requires multi-block MOV design capable of dissipating lightning impulses $\mathrm{I}_{\mathrm{t}}=40 \mathrm{kA} 8 / 20 \mu \mathrm{s}$ from the $\mathrm{MOV}$ components of Siemens has the code B32K275 with $\mathrm{W}=360 \mathrm{~J}$ with a threshold voltage error of $\Delta \mathrm{V} \%= \pm 10 \%$. The simulation circuit is shown in Figure 5 with the number of MOV elements $\mathrm{n}=5$.

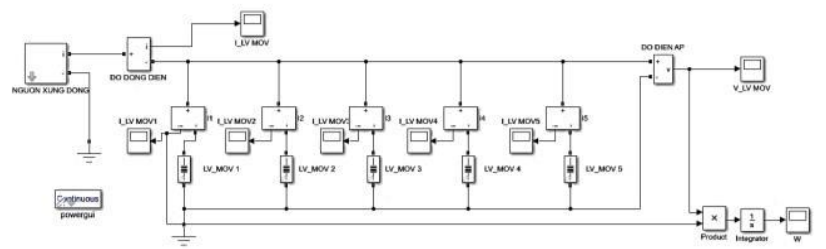

Fig. 5 The MOV multi-block simulation circuit consists of 5 MOV elements B32K275

For $\mathrm{MOV}_{1}$ there is a threshold voltage error of $-10 \%$ (MOV must suffer the largest current of all MOV elements) and the remaining $\mathrm{MOV}_{\mathrm{s}}$ have a threshold voltage error of $+10 \%$. The current pulse shape through $\mathrm{MOV}_{1}$ is shown in Fig.6, the horizontal voltage pulse shape through $\mathrm{MOV}_{1}$ is shown in Fig.7, and the dissipation energy shape of $\mathrm{MOV}_{1}$ is shown in Fig.8.

From Fig.8, determine the largest energy dissipation of $\mathrm{MOV}_{1}$ is $\mathrm{W}_{\text {max }}=343 \mathrm{~J}<\mathrm{W}_{\mathrm{cp}}=360 \mathrm{~J}$. Choose $\mathrm{n}=5$, that means the ability to dissipate lightning impulse rated of MOV in multi-block MOV is $5 \times 25=125 \mathrm{kA} 8 / 20 \mu \mathrm{s}$.

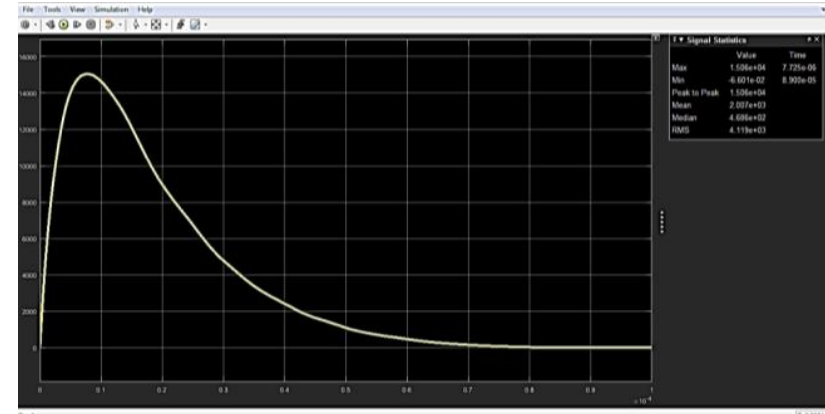

Fig.6 The current pulse shape through $\mathrm{MOV}_{1}$

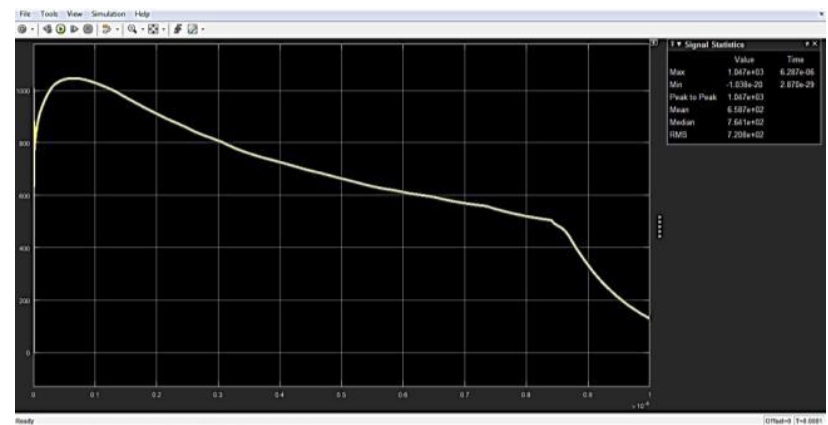

Fig.7 The horizontal voltage pulse shape through MOV

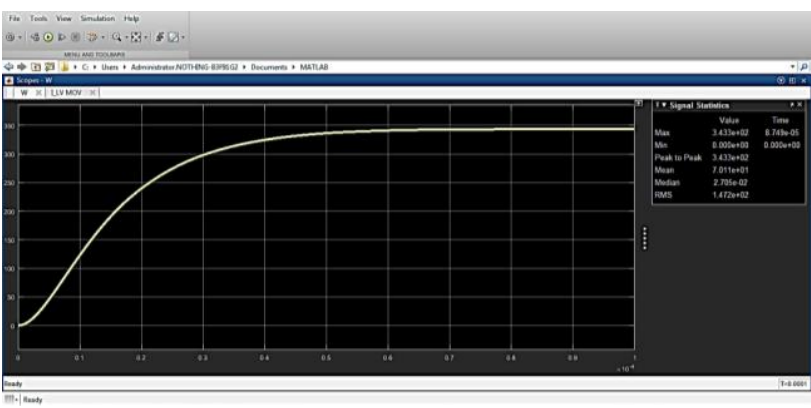

Fig.8 The dissipation energy shape of $M O V_{l}$

Similarly, using the power dissipation method, determine the number of MOV elements of multi-block MOVs with rated pulse currents of $25 \mathrm{kA}, 40 \mathrm{kA}, 50 \mathrm{kA}, 70 \mathrm{kA}$ and

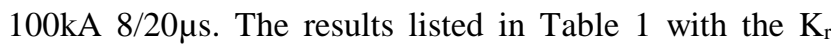
reserve factor are determined by the ratio of the total of the rated pulse current of MOV elements to the rated pulse current of multi-block MOV.

Table 1: The number of MOV elements of the common multi-block MOV

\begin{tabular}{|c|c|c|c|}
\hline \multirow[b]{2}{*}{ Multi-block MOV } & \multicolumn{2}{|c|}{ The number of MOV elements } & \multirow{2}{*}{$\begin{array}{c}\text { The reserve } \\
\text { factor } K_{\mathbf{r}}(\%) \\
(1) /(2)\end{array}$} \\
\hline & $\begin{array}{c}\mathrm{B} 32 \mathrm{~K} 275^{(1)}, 25 \mathrm{kA} 8 / 20 \mu \mathrm{s} \\
\Delta \mathrm{V} \%= \pm 10 \%\end{array}$ & $\begin{array}{c}\mathrm{S} 20 \mathrm{~K} 275^{(2)}, 8 \mathrm{kA} 8 / 20 \mu \mathrm{s} \\
\Delta \mathrm{V} \%= \pm 10 \%\end{array}$ & \\
\hline $25 \mathrm{kA} 8 / 20 \mu \mathrm{s}$ & - & 9 & $-/ 2,9$ \\
\hline $40 \mathrm{kA} 8 / 20 \mu \mathrm{s}$ & 5 & 16 & $3,1 / 3,2$ \\
\hline $50 \mathrm{kA} 8 / 20 \mu \mathrm{s}$ & 7 & 21 & $3,5 / 3,3$ \\
\hline $70 \mathrm{kA} 8 / 20 \mu \mathrm{s}$ & 10 & 37 & $3,6 / 4,2$ \\
\hline $100 \mathrm{kA} 8 / 20 \mu \mathrm{s}$ & 15 & 45 & $3,7 / 3,6$ \\
\hline
\end{tabular}




\section{CONCLUSION}

This paper presents the method of determining the number of MOV elements in parallel-couple of multiblock MOV according to the energy dissipation method allowed with the support of Matlab software and modelling and simulation techniques.

The number of MOV elements of a common multiblock MOV with 25kA, 40kA, 50kA, 70kA, and 100kA $8 / 20 \mu$ s rated pulse currents are listed as a lookup table that allows multi-block MOV manufacturers to reference during the design process and Producing multi-block MOV in reality.

\section{ACKNOWLEDGEMENTS}

This research was supported by Ho Chi Minh City University of Technology and Education, and Dong Nai Technology University.

\section{REFERENCES}

[1] Le Quang Trung, Quyen Huy Anh, Vu Phan Tu. Surge Protector on the Power Lines, Considering the Influenced Factor. IEEE International Conference on System Science and Engineering ICSSE 2017.

[2] QuyenHuy Anh, Le Quang Trung. Selection Guide for Low Voltage Surge Protection; International Journal of Engineering Research \& Technology 10/2017.

[3] Carlos Avendaño, Henry Ibáñez. Design of SPDs class I for low voltage electric systems, using combination of metal oxide varistors. Helmuth Ortiz Universidad Distrital "Francisco José de Caldas", 2015.

[4] SaadDauGecol; Modeling of metal oxide surge arresters as elements of overvoltage protection systems; International Conference on Lightning Protection (ICLP), 2012.

[5] Chryssa Nasiopoulou, Eleftheria Pyrgioti. Performance of Surge Arresters in a Low Voltage Distribution System. International Conference on Lightning Protection (ICLPj, Vienna, Austria, 2012.

[6] SIOV metal oxide varistors, Data Book, TDK 2018. 